This is an electronic reprint of the original article. This reprint may differ from the original in pagination and typographic detail.

Author(s): Kiili, Carita; Leu, Donald J.; Marttunen, Miika; Hautala, Jarkko; Leppänen, Paavo H.T.

Title: $\quad$ Exploring early adolescents' evaluation of academic and commercial online resources related to health

Year: $\quad 2018$

Version:

Please cite the original version:

Kiili, C., Leu, D. J., Marttunen, M., Hautala, J., \& Leppänen, P. H. (2018). Exploring early adolescents' evaluation of academic and commercial online resources related to health. Reading and Writing, 31(3), 533-557. https://doi.org/10.1007/s11145-0179797-2

All material supplied via JYX is protected by copyright and other intellectual property rights, and duplication or sale of all or part of any of the repository collections is not permitted, except that material may be duplicated by you for your research use or educational purposes in electronic or print form. You must obtain permission for any other use. Electronic or print copies may not be offered, whether for sale or otherwise to anyone who is not an authorised user. 


\title{
Exploring Early Adolescents' Evaluation of Academic and Commercial Online Resources Related to Health
}

\author{
Carita Kiili (Corresponding author) \\ Department of Education, University of Oslo and \\ Department of Education, University of Jyvaskyla \\ Donald J. Leu \\ Neag School of Education, University of Connecticut \\ Miika Marttunen \\ Department of Education, University of Jyvaskyla \\ Jarkko Hautala and Paavo H.T. Leppänen \\ Department of Psychology, University of Jyvaskyla
}

\author{
Author note \\ Contact information of corresponding author: \\ P.O. Box 1092, Blindern \\ 0137 Oslo, Norway \\ c.p.s.kiili@iped.uio.no \\ Phone: +358443031545
}

This work was supported by the Academy of Finland (No. 274022). We are also grateful to

Sini Hjelm, Sonja Tiri and Paula Rahkonen for their valuable work with the data collection and data management. 


\title{
Exploring Early Adolescents' Evaluation of Academic and Commercial Online Resources Related to Health
}

\begin{abstract}
This study assessed the ability of 426 students (ages 12-13) to critically evaluate two types of online locations on health issues: an academic resource and a commercial resource. The results indicated limited evaluation abilities, especially for the commercial resource, and only a small, partial association with prior stance and offline reading ability. Only about half (51.4\%) of the students questioned the credibility of the commercial online resource and only about $19 \%$ of the students showed an ability to fully recognize commercial bias. Wide variation existed in students' ability to evaluate online information, as approximately onefourth of the students performed poorly when evaluating the overall credibility of both online resources and one-fourth performed well. Logistic regression models showed that offline reading skills accounted for only $8.8 \%$ of the variance for the academic online resource and $15.1 \%$ of that for the commercial resource. No association appeared between evaluation and background knowledge, although an association with prior stance was observed for each online resource. The results are discussed in light of previous research and the need to pay greater attention to the critical evaluation of online resources during classroom instruction.
\end{abstract} Keywords: evaluation, online reading, digital literacy, adolescents, critical reading 
The Internet, characterized by the absence of traditional gatekeepers and a diverse set of voices, requires an especially sophisticated level of critical evaluation, and thus presents challenges to readers (Gasser, Cortesi, Malik, \& Lee, 2012). A reader's inability to evaluate online information may have serious political, social, health, or economic consequences (Flanagin \& Metzger, 2008), with young people especially vulnerable to misleading information owing to their still limited cognitive development and life experience (Eastin, 2008). Moreover, children under the age of twelve or thirteen may experience difficulty in mastering the argumentative text genre commonly utilized in persuasive messages online (cf. Brassart, 1996).

The ability to think critically about these messages has become an important issue for the study of online reading (Fabos, 2008). While research on information intertwined with commercial elements (e.g., Bråten, Strømsø \& Salmerón, 2011; Howe \& Teufel, 2014; Kammerer, Kalbfell, \& Gerjets, 2016) has been conducted with college students and adults, little is known how younger students evaluate commercial information when reading online. This knowledge would provide both teachers and policy makers with a more comprehensive understanding of evaluation skills development and support the important work with younger students that may be required. This study explored the ability of Finnish $6^{\text {th }}$ grade students to evaluate the academic and commercial online resources they were presented with during an online research task on health issues.

\section{Theoretical Frameworks}

This study drew on theoretical frameworks originally developed for informational reading offline (Britt, Perfetti, Sandak, \& Rouet, 1999; Perfetti, Rouet, \& Britt, 1999) and online (Brand-Gruwel, Wopereis, \& Vermetten, 2005; Leu, Kinzer, Coiro, Castek, \& Henry, 2013). Both frameworks highlight the importance of evaluating information during reading. 
Theoretical perspective of multiple document comprehension (Britt et al., 1999; Perfetti et al., 1999) emphasizes paying attention to source information of documents (e.g., author expertise, credentials, affiliation and motives, along with the document type, date, and other elements), when integrating information from them with the aim of building a global understanding about an issue. Attending to source information enables readers to evaluate documents, establish links between a source and the document's content, form relationships with sources, and organize content. Establishment of the source-content link may proceed in several ways. Attention to source information may affect the types of documents that readers select, and how they process and interpret them (see Bråten, McCrudden, Lund, Brante, \& Stømsø, 2017). Alternatively, contradictory information in two documents may trigger readers to pay attention to the authority of the document (see Rouet, Le Bigot, de Prereyra, \& Britt, 2016). Although approaches to multiple document comprehension were originally developed for the reading of printed documents, they have also been applied to online documents (e.g., Le Bigot \& Rouet, 2007; Strømsø, Bråten, Britt, \& Ferguson, 2013). In the present study, this approach informed how the evaluation of online resources was conceived.

The evaluation of information has also been a focus of frameworks developed to describe the processes and practices important when reading to learn on the Internet. The frameworks of online research and comprehension (Leu et al., 2013) and information problem solving on the Internet (Brand-Gruwel et al., 2005) define the processes and components important to reading and learning utilizing online information. These two frameworks have theorized rather similar component structures during online reading/problem solving: 1) identifying/defining the question/problem; 2) locating/searching for information; 3) evaluating/scanning information; 4) synthesizing/processing information; and 5) communicating/presenting information. Online, effective readers continuously evaluate information relevance and quality when making decisions about what to read, how 
to read, and how to utilize texts in solving problems. This perspective was used in the present study, where students' abilities in evaluating online resources were measured in the context of a complete online reading and problem-solving task.

Multiple research communities are currently investigating evaluation processes when reading multiple documents offline or online. As a result, different terms are used in defining reading materials, their features, and specific processes and practices enacted during reading (see Goldman \& Scardamalia, 2013). In the present study, we chose to use the term online resource when referring to reading materials, as it best reflects the nature of online information that is complex, interconnected, and presented in multiple modalities (e.g., Hartman, Hagerman, \& Leu, in press). In addition, we use the term evaluation of credibility when referring to students' evaluative comments concerning either author expertise or the trustworthiness of the content in the assigned online resources.

\section{Evaluation of Credibility}

Credibility can be defined as the believability of an online resource including its perceived quality (Flanagin \& Metzger, 2008; Tseng \& Fogg, 1999). According to Tseng and Fogg (1999), people tend to evaluate multiple dimensions in order to arrive at an overall assessment of credibility. However, two components are often thought to be prime of importance: expertise and trustworthiness of the content (Flanagin \& Metzger, 2008; Fogg et al., 2002; Tseng \& Fogg, 1999). Expertise concerns the knowledge, competence and reputation related to the online resource. Trustworthiness refers to readers' perceptions of well-intentioned, truthful, and unbiased information capturing the goodness or morality of the content presented in an online resource. While the evaluation of expertise answers the question, "Whom to trust?" the evaluation of trustworthiness answers the question, "What to trust?" (Andreassen \& Strømsø, 2012).

But what are the features of online resources that may assist readers when evaluating 
information as misleading or biased? Walton (1991) identified several elements of bias that can be utilized during the evaluation of information. First, bias refers to a lack of appropriate balance or neutrality in the argumentation used, meaning that the online resource overstrongly supports one side of the argument. Second, biased information lacks an appropriate level of doubt in its argumentative content. In addition, bias can be often identified with a particular position from which the author(s) stands to gain, for example, financial, or political interests.

Health-related online resources form an important informational context for children and adolescents. These may include scientific information but also intentionally or unintentionally biased information (Bates, Romina, Ahmed, \& Hopson, 2006; MorahanMarting, 2004). For example, websites targeted at children may include both overt and covert advertising, thereby requiring children to deconstruct hidden messages (Kervin, Jones, \& Mantei, 2012). Howe and Teufel (2014) found that even undergraduate students and adults had difficulty noticing integrated forms of advertising, such as sponsored content in news websites, compared to traditional banner-type advertisements. The lack of critical engagement with misleading or commercially biased health-related information, given its potential consequences, raises serious concerns.

\section{Reading Skills and Prior Knowledge in Relation to the Evaluation of Online Resources}

Offline reading fluency and reading comprehension build a foundation for successful online reading (Leu et al., 2013). Among younger students, reading fluency appears to play an important role in offline reading (Fuchs, Fuchs, Hosp, \& Jenkins, 2001). No previous research on fluency, however, has evaluated the extent to which fluency is associated with the evaluation of online resources.

Online and offline reading skills are layered in complex ways (Leu, Forzani, Rhoads, Maykel, Kennedy, \& Timbrell, 2015) such that the two are only partially correlated (Coiro, 
2011a; Hahnel, Goldhammer, Naumann, \& Kröhne, 2016). As far as we know, there is no research on how offline reading comprehension skills predict the evaluation of online resources that differ in quality. This information would be useful for designing instruction that prepares students for the new demands of online reading. We included both reading fluency and reading comprehension in the design of this study.

During reading comprehension, the prior knowledge that readers bring to texts plays an important role in their efforts to build a coherent representation of the text (Kintsch, 1998). An additional factor that may play a role, especially when reading about controversial issues, is a reader's prior beliefs, or stance, on an issue. This may affect how a reader interprets textual evidence (Nickerson, 1998) or evaluates websites (van Strien, Kammerer, BrandGruwel, \& Boshuizen, 2016).

\section{The present Study}

This study explores sixth graders' evaluation skills when engaging in an online research task concerning health issues. While previous work has shown the difficulty that students across a range of developmental levels experience in critically evaluating online information (Kiili, Laurinen, \& Marttunen, 2008; Macedo-Rouet, Braasch, Britt, \& Rouet, 2013; Walraven, Brand-Gruwel, \& Boshuizen, 2009), this study focuses on specific differences in the evaluation of two types of online resources that are frequently encountered by students: academic and commercial. The study also sought to understand the role of several background factors during the evaluation of online resources.

Three issues were explored:

1. How do elementary school students (ages 12 to 13) perform in the evaluation of academic and commercial online resources? 
a. How well do elementary school students evaluate online resources in terms of a) author expertise and b) the overall credibility of the online resource?

b. Do elementary school students perform similarly when evaluating the overall credibility of academic vs. commercial online resources?

2. How do elementary school students justify their evaluations of the overall credibility of academic and commercial online resources?

3. How are background factors, such as prior stance, prior knowledge, reading fluency and reading comprehension related to students' ability to evaluate the overall credibility of online resources?

\section{Methods}

\section{Participants}

Sixth graders (12-13 years of age) were recruited from eight Finnish elementary schools, serving both suburban and rural populations $(n=545)$. Of these, 441 parental permissions were returned, and 426 students who were in school on the day of the data collection ( 219 boys and 207 girls) participated in the study. All the students in the participating classrooms completed the reading tasks but only students whose parents provided an informed consent were included in the study. Of the 426 participants, 415 completed all the offline and online reading measures.

\section{Prior Stance and Prior Knowledge Measures}

Students' prior stance on energy drinks was measured with a multiple-choice question. Students were asked to choose the stance that best represented their opinion: 1) Selling energy drinks to children under 15 should be prohibited (negative stance); 2) Selling energy drinks to children under 15 years of age should be allowed (positive stance); 3) I do not have a clear opinion on the issue (no opinion). 
Students' prior knowledge about energy drinks and their health effects was measured with seven, multiple-choice items. Each included one correct answer, two incorrect answers, and a "don't know" option. The reliability (KR-20) for the total score on the measure was .885 .

\section{Reading Measures}

Students' reading skills were measured with three reading fluency tests and one reading comprehension test. A reading fluency composite measure was obtained by conducting factor analysis (Principal Axis Factoring, Promax rotation and using an eigenvalue of 1 as a criterion) for the three timed fluency tests: a word chain test (Nevala, \& Lyytinen, 2000), a word identification test (Lindeman, 1998), and a pseudoword reading fluency test (Eklund, Torppa, Aro, Leppänen, \& Lyytinen, 2015). The Principal Axis Factor analysis (PAF) resulted in one factor explaining $69.7 \%$ of the variance. The factor loadings were 0.86 for the word chain test, 0.70 for word identification, and 0.66 for pseudoword reading fluency. The factor scores for the PAF-derived factor were used as a composite score for reading fluency level.

To assess students' reading comprehension skills, we used Lindeman's (1998) Alaasteen lukutesti (ALLU) reading test for primary school. ALLU consists of a normreferenced reading test battery designed for students from 6 to 12 years of age. In our study, students read one expository text and answered 12 multiple-choice questions. Each question was followed by four alternatives, one of which was correct. According to the test manual (Lindeman, 1998), the Kuder-Richardson reliability coefficient for the reading comprehension measure with two expository texts is 0.74 .

\section{Task and Materials}

This study examined students' evaluations of two online resources in the context of a larger online inquiry task in which students were asked to explore the health effects of energy 
drinks. During the larger task, students read four online resources, while for this study they were asked to evaluate two of them. These two resources were presented as the second and third resources in the complete online inquiry task.

Walton's (1991) views on the features of bias were used to create the two resources that students evaluated. These differed in several dimensions: purpose (providing information vs. commercial purpose); balance of argumentation (multiple sides vs. largely one-sided); and doubt (conditional vs. unconditional). Authentic websites were used to inform the preparation of these online resources.

The academic online resource (see Appendix A) was affiliated with a university; a health studies researcher answered questions commonly put by parents about energy drinks. At the end of the document, the references used in the answers were listed. This resource provided facts on health issues related to the use of energy drinks without taking a position either for or against their use. Instead, it informed readers about the circumstances in which energy drinks were considered safe to use and those when they are not.

The commercial online resource (see Appendix B) was a press release published by a fictional manufacturer to promote sales of a new energy drink. In the press release, the head of the marketing department took a positive stance towards the health effects of energy drinks. She put forward several arguments for the use of energy drinks, and it was only in the last line of the text that she expressed a mild concern over their consumption: "...however, too much is too much". Thus, the argumentation can be regarded as distinctly one-sided. In addition, the resource can also be regarded as representing a manufacturer whose financial interests are mirrored in the arguments of the text. Further, some of the information provided in this online resource was somewhat inconsistent with information provided in the two preceding resources that the students had just read. This sequence of resources provided students with the opportunity to consider corroborative evidence. 
Scaffolds embedded in the evaluation tasks. The task of evaluating the credibility of the online resources was structured with questions that appeared sequentially in a chat window, each requiring a response. The questions were: 1) "Who is the author of the web page?"; 2) "Is she or he an expert in the health effects of energy drinks? Why do you think so?"; 3) "Is the information presented on the web page credible? Why do you think so?". Thus, the evaluation of online resources was sequenced to enable students to broaden and deepen their thinking, step-by-step, and then provide their overall evaluation of the credibility of the online resource.

\section{Data Collection}

Data were collected in three separate sessions. During the first two sessions, the students completed the reading fluency and comprehension tests. In the third session, the students first completed the stance evaluation and the prior knowledge test, and then the online inquiry task. In this session, the students worked in a classroom with laptops. The online inquiry task was run from the local server on each laptop. Two researchers were present in the classroom and helped students if they encountered technical problems.

\section{Data Analysis}

Scoring students' performance in the evaluation tasks. Credibility was operationalized with two variables. The first variable focused on the ability to evaluate the credibility of the online resource from the perspective of author expertise. The second variable, overall credibility of the online resource, focused on the ability to evaluate the credibility of the online resource from a broader perspective that included both author expertise and trustworthiness of content. We recognize the overlap in these two variables, but nevertheless wanted to evaluate author expertise both separately and as one element of the credibility in a broader sense. Both the accuracy and quality of student responses were 
evaluated. We included the qualitative aspects of their justifications to provide a more complete and richer estimate of their evaluation skills.

Students' answers to the questions on author and overall credibility were scored according to a four-point rubric (see Tables 1 and 2). In scoring author expertise, students were awarded with one point for an accurate evaluation (the author of the academic online resource is an expert on health issues / the author of the commercial resource is not an expert). Students were further awarded with one or two additional points based on the quality of their justification for each correct evaluation. In scoring the overall credibility of the online resource, students were awarded with one point for a correct evaluation (information on the academic online resource is credible / information on the commercial resource is not credible). Students were also awarded with one or two additional points depending on the quality of their justification(s) for each correct evaluation. Two independent coders scored $20 \%$ of the answers for all four variables, attaining Kappa values of $0.947-0.983$. These scores were also used in the analysis of the third and fourth research questions, shown below.

----TABLE 1 HERE----

----TABLE 2 HERE----

\section{Coding of students' justifications for their overall credibility evaluations. To}

explore how students justified their evaluations of the overall credibility of the online resources, qualitative analytic methods were used to separate relevant justifications from irrelevant ones for both author expertise and the trustworthiness of the content, and to identify sub-categories within each area (see Table 3). Abductive (Onwuegbuzie \& Teddlie, 2003) procedures were used. The categories emerged through content analysis (Krippendorff, 2004) that was applied to previously established categories (Coiro, Coscarelli, Maykel, \& Forzani, 2015; Kiili et al., 2008) and theoretical considerations (Tseng \& Fogg, 1999; Walton, 1991) but included inductive procedures (Bogdan \& Biklen, 2003) to more 
accurately represent the justifications observed in the data. The unit of analysis was the expression with which students justified their evaluations, and thus students' answers could include one or more justifications. Descriptive frequency analysis was applied to these categories. Two independent coders evaluated $27 \%$ of the students' answers, reaching $84.3 \%$ agreement on the justifications for the academic resource and $83.3 \%$ on those for the commercial resource.

\section{----TABLE 3 HERE----}

Statistical analyses. Because the distribution of the students' scores on overall credibility evaluation was not normally distributed (Figure 2), we used nonparametric statistical analyses. A contingency table analysis was conducted to find out whether students credibility evaluation scores were consistent across the two types of online resources, i.e., whether the observed frequencies (OF) differed statistically from the expected frequencies (EF) derived from the binomial distribution. Because we had two related samples both scored according to the four-point rubric we chose to use a McNamar-Bowker test. A post-hoc McNamar test was conducted to test whether students who scored extreme values ( 0 or 3$)$ for their credibility evaluations of the academic online resource, also scored extreme values ( 0 or 3) for the commercial resource. The post-hoc tests were only conducted with extreme values, as these were the only categories where the observed frequencies differed notably from the expected frequencies (see Table 5).

Binomial logistic regression analysis with the enter method was used to explore how offline reading fluency and reading comprehension ability were associated with evaluating the overall credibility of the two types of online resources. Students' evaluation scores were recoded into dichotomous outcome variables: scores 0 and 1 were recoded as low performance and scores 2 and 3 were recoded as high performance. Regression coefficients of logistic regression are reported as odds ratios with a $95 \%$ confidence interval. 


\section{Results}

\section{Descriptive Statistics for Background Variables}

Table 4 shows descriptive statistics for the measured background variables. All the variables were fairly symmetrical, as the coefficients of skewness ranged from -0.45 to 0.39 . The majority of the students (62.7\%) expressed either a negative stance on allowing energy drinks for children under 15 years of age or they did not have a clear opinion on the issue (29.0\%). Only $8.3 \%$ of students expressed a positive stance on allowing energy drinks.

\section{----TABLE 4 HERE----}

\section{How Do Students Perform in the Evaluation of Academic and Commercial Online Resources?}

Author expertise. Figure 1 shows the students' scores for their evaluations of author expertise for the academic and commercial online resources. For many students, the evaluation of expertise, especially of a commercial resource, seemed rather difficult. Nearly $40 \%$ of the students expressed no doubts about the author's expertise (scoring 0 points) when reading the commercial resource. Less than one-third of the students successfully evaluated author expertise for the academic $(33.1 \%)$ or the commercial $(30.5 \%)$ resource, scoring three points.

\section{----FIGURE 1 HERE----}

Overall credibility of the online resource. Figure 2 shows that nearly half of the students (48.6\%) failed to doubt the credibility of the information in the commercial online resource (scoring 0 points). Only $36.4 \%$ justified their accurate evaluation of the commercial online resource: $19.0 \%$ of students did so by recognizing commercial bias and another $17.4 \%$ provided some other relevant justification for their evaluation. Students performed better in evaluating the academic online resource. Only $8.2 \%$ failed to provide an accurate evaluation of the academic online resource. Almost $64 \%$ justified their accurate evaluation of the 
academic online resource: $52.1 \%$ of students provided one justification ( 2 points) and $11.5 \%$ provided at least two justifications (3 points).

----FIGURE 2 HERE----

\section{Similarity of performance in the evaluation of overall credibility for the}

academic and commercial resource. Table 5 indicates that the number of students who

scored low ( 0 or 1 points) in both credibility evaluation tasks was rather high, 109 students $(25.6 \%)$ in total. Exactly the same number and percentage of students $(n=109 ; 25.6 \%)$ scored high in both tasks ( 2 or 3 points). The McNemar-Bowker analyses revealed an association between the performances of the two credibility evaluation tasks $\left(\chi^{2}(6)=186.7, p\right.$ $<.001)$. The distribution of scores appeared to be a somewhat bipolar. Post hoc analyses showed that a large number of students scored extreme values of either three points (Observed Frequency, $\mathrm{OF}=22$; Expected Frequency, $\mathrm{EF}=9.3)$ or zero points $(\mathrm{OF}=24 ; \mathrm{EF}$ $=17.0)$ in both evaluation tasks and that in both cases the numbers were greater than expected, $p<.05$.

----TABLE 5 HERE----

\section{How Do Students Justify Their Evaluations of the Online Resources?}

Table 6 indicates that $355(83.3 \%)$ of all 426 students provided an appropriate evaluation along with an attempt to justify their evaluation for the academic online resource compared to only $192(45.1 \%)$ for the commercial resource. The justifications were mostly relevant; $81.4 \%$ for academic and $83.4 \%$ for commercial online resource. In their evaluations of the academic resource, students relied more on the expertise of the author (54.4\% of justifications) than the trustworthiness of the content (27.0\%). In their evaluations of the commercial resource, students paid more attention to the trustworthiness of the content (73.2\% of justifications) than author expertise (10.2\%). In total, only 111 of the 426 students $(26.1 \%)$ identified features of bias in the commercial resource: $81(19.0 \%)$ noted its 
commercial purpose; 23 (5.4\%) used corroboration and noticed information conflicting with that in the other resources; and $7(1.6 \%)$ paid attention to the balance of argumentation in the text.

A systematic evaluation of online resources requires students to take multiple perspectives into account. However, only $11.5 \%$ of all students presented two or more relevant justifications for their overall credibility evaluation of the academic resource. Only two students provided either three or four relevant justifications. For the commercial resource, the proportion of students $(3.3 \%)$ offering more than one relevant justification for their overall evaluation was even smaller.

\section{----TABLE 6 HERE----}

\section{How are Background Factors Related to Students' Ability to Evaluate the Overall Credibility of Online Resources?}

Prior stance. The evaluation of author expertise and the overall credibility of the online resources were evaluated in relation to prior stance. A significant difference in the evaluation of author expertise was observed between the prior stance groups for both the academic $\left(X^{2}=9.66 ; p<0.01\right)$ and commercial online resources $\left(X^{2}=8.09 ; p<0.05\right)$. In the evaluation of the overall credibility of the online resources, a significant difference only was found for the commercial resource $\left(X^{2}=7.99 ; p<0.05\right)$. The students' performance across the evaluation tasks showed a similar pattern. The students with a negative stance scored highest, students with no opinion second highest, and students with a positive stance lowest (see Appendix C for descriptive statistics and pairwise comparisons.)

Prior knowledge. Students' prior knowledge was unrelated to their evaluation task performance. Correlations between prior knowledge and the evaluation variables were either non-existent (two variables; $r_{s}=.052-.062 ; n s$.) or very low (two variables; $r_{s}=.096-.124 ; p \mathrm{~s}$ $<0.05)$. 
Reading fluency and reading comprehension. The logistic regression models for both types of online resources (academic and commercial) with the evaluation of the overall credibility of the resource as a dependent variable are presented in Table 7. Both models (Models A and B) were statistically significant, accounting for $8.8 \%$ and $15.1 \%$ of the variance (Nagelkerke's $\mathrm{R}^{2}$ ) in the students' overall credibility evaluation of the academic and commercial resources respectively. Only reading comprehension was a significant predictor for the evaluation of the academic online resource (Model A), while both reading fluency and reading comprehension were statistically significant predictors for the evaluation of the commercial online resource (Model B).

On the basis of the students' reading skills, both Model A (academic resource) and Model B (commercial resource) were able to classify the students with the same degree of accuracy (Model $\mathrm{A}=65.1 \%$ accuracy; Model $\mathrm{B}=64.6 \%$ accuracy) into the skilled and unskilled groups of credibility evaluators. Model A was able to predict the evaluation of overall credibility more accurately for skilled evaluators $(89.8 \%)$ than unskilled evaluators (21.9\%). Model B was able to predict the evaluation of overall credibility more accurately for unskilled evaluators $(81.3 \%)$ than skilled evaluators $(35.9 \%)$.

\section{----TABLE 7 HERE----}

\section{Discussion}

This study sought to increase our understanding of sixth graders' abilities to evaluate multiple online resources (academic and commercial) related to a health issue, a problemsolving task of a kind they frequently encounter both in and out of school (Gray, Klein, Noyce, Sesselberg, \& Cantrill, 2005). This understanding is particularly important given the essential role of evaluation skills both for the productive use of online information in learning (Wiley et al., 2009) and the safe use of online information in students' personal lives (Byron, 
2008). The latter is particularly important in early adolescence, when issues related to growth, health, sexuality, and ideologies become important (Eccles, 1999).

The results indicated that students are limited in their ability to evaluate online information that may be important in their lives. Identifying elements of bias, in particular, proved difficult for many students. Fewer than one out of five (19\%) students recognized the commercial purpose of an online resource and only an additional $17 \%$ provided some other relevant justification for their critical evaluation. In particular, justifications requiring a careful exploration of the content (e.g., evaluating balance in the argumentation) or corroborating claims with information from other resources were seldom observed (cf. Eastin, Yang, \& Nathanson, 2006).

It should be cause for concern that almost half of the students failed to question the credibility of the commercial online resource as a source of health-related information despite the presence of clearly visible commercial elements (logos, author's profession, etc.). Perhaps the professional tone of the text concealed the commercial purpose from many students, an issue that older readers might also sometimes find difficult (Howe \& Teufel, 2014). Further, it might be that students of this age are not yet fully equipped to identify persuasive messages (Brassart, 1996). Additional research is clearly needed to investigate the identification of online bias from a fully developmental perspective, both at younger and older ages. This would provide us with a better understanding of when students are cognitively equipped to identify overt and covert commercial messages online and how instructional practices in different school grades might support students in becoming more critical readers of online information. Another explanation for students' difficulties in identifying bias might be that students are not used to encountering resources in a school context that vary as widely in quality as the present examples. To ensure that all students have opportunities to identify the 
elements that make one resource more credible than another, students may need opportunities at school to evaluate different kinds of age-appropriate online information.

Considerable variation was observed in students' ability to evaluate online information, indicating differential readiness to face the wide variety of online information related to health issues. The combined scores for evaluating academic and commercial online resources showed a bipolar distribution. Some students appear to be well equipped to evaluate different types of online resources whereas the others seem to lack the ability to critically evaluate any type of online resource. This increases these students' vulnerability to misleading information. The present results are in line with previous studies on students' evaluation skills in early adolescence or adolescence (e.g., Coiro et al., 2015; Kiili et al., 2008). Since evaluation skills vary widely, there is an important need for assessment in this area and for differentiating instruction according to skill level. Some students will benefit from starting with simpler strategies and easier texts whereas more advanced students will benefit from opportunities to practice complex evaluation tasks that demand careful exploration along with comparing and contrasting multiple resources. Recent work also suggests that brief instructions to focus on source credibility may increase the value placed on author expertise (Bråten, McCrudden, Lund, Brante, \& Stømsø, 2017).

The other issue of concern is that only a small proportion of the students provided multiple justifications for their credibility evaluations irrespective of the type of online resource. It is possible that children of this age may not yet have the cognitive resources required for managing multiple information resources (Eastin et al., 2006). It may also be that students have not yet had enough opportunities to practice multiple evaluation strategies or they have not been sufficiently engaged in discussions about the importance of evaluating resources from multiple perspectives. Students with a limited strategic repertoire would benefit from instruction that models the use of different types of evaluation strategies (see 
Coiro, 2011b), including both expertise as well as trustworthiness. To understand why it is important to utilize multiple strategies in evaluation, students also need concrete experiences with the potential consequences of relying on only one aspect of evaluation.

Offline reading skills, reading fluency and comprehension combined predicted only $8.8 \%$ of student performance in the evaluation of an academic online resource and $15.1 \%$ in that of a commercial online resource. This may suggest that offline reading skills are necessary but not sufficient for the skillful evaluation of online resources. It could be that offline measures of comprehension, and offline reading in general, do not typically require the same amount of critical evaluation of resources as was required in the present online reading task. Traditional gatekeepers (editors, authors, publishers, etc.) are more universally present in the development of offline material, thereby often reducing demands for critical evaluation. This is not to suggest that critical evaluation is not required offline, but simply that the demand for this skill is often somewhat less pressing than is required online.

In sum, however, we consider that these results point to the importance of offline reading proficiency for the evaluation of online resources. Poorer offline readers, for example, were more likely to struggle with online evaluation, suggesting that offline reading skills are building blocks for critical evaluation skills online. In particular, online evaluation strategies that required deep engagement with content also seemed to require good offline comprehension skills. However, especially in evaluating the commercial resource, the good offline readers did not necessarily perform well. Additional research is needed to more fully understand the reasons for their difficulties. This would help teachers offer targeted support to help these students overcome the obstacles they face in evaluating commercially biased resources.

The lack of a strong relationship between offline reading achievement levels and online reading evaluation is consistent with previous research. It appears that online reading 
comprehension is not isomorphic with offline reading comprehension (Afflerbach \& Cho, 2010; Coiro \& Dobler, 2007). Afflerbach and Cho reviewed 46 studies focused on reading strategy use during Internet and hypertext reading. Their analysis showed evidence of strategies that "appear to have no counterpart in traditional reading" (p. 217). Many strategies centered around a reader's ability to apply methods to reduce their levels of uncertainty while navigating and negotiating appropriate reading paths in a shifting problem space. The results of this study suggest that the evaluation of online resources may also contribute to the lack of an isomorphic relationship between offline and online reading.

It may be that unique evaluation skills are required during online reading. A study by Bråten, Strømsø, and Britt (2009) reported that online critical evaluation skills appeared to be separate and independent from offline reading skills. It could be that online reading requires more of an emphasis on independent, critical evaluation than does offline reading. In schools, teachers usually provide students with pre-selected materials that may not require the same amount of critical, thoughtful evaluation of information as is required online. For example, author information may not have received much attention in classrooms using pre-selected resources.

The knowledge that readers bring to a text plays an important role in their comprehension of offline material (Kintsch, 1998); hence it was somewhat surprising to find that prior knowledge was not related to student performance in the evaluation tasks. This may owe to the fact that prior to their evaluation tasks all the students read one additional online resource which may have contributed additional prior knowledge across the group. It may also be another aspect of online reading that differentiates it from offline reading. Previous work (Leu et al., 2015) also found no significant association between prior knowledge and online reading. It is important to note, however, that prior stance was associated with 
performance on most tasks, indicating that students with a negative stance performed better in most of the evaluation tasks.

It is also important to note that the results of this study only tell us about students' ability to evaluate online resources in the presence of scaffolding. Previous studies have shown that students do not always evaluate online information spontaneously (Kiili et al., 2008; Walraven et al., 2009). It is thus possible that students might not have performed even to the level as did without the scaffolding supplied in this study. According to the document model (Britt et al., 1999; Perfetti et al., 1999), attending to author information and other features of a resource is a prerequisite for the evaluation of an author and his or her expertise and its connections to the quality of the content. Because the students in this study were prompted to attend to author expertise, they may have been able to utilize this information in their final credibility evaluation. The results may not tell us what happens when students work independently online, but rather only what they are capable of doing. Another limitation is that we only measured students' skill in evaluating one academic and one commercial resource. There may have been something distinctive in the resources we used that affected these results. Research with several online resources of each type is needed to obtain a broader and more complete understanding of online evaluation.

\section{Conclusion}

The results of this study in which students in early adolescence evaluated an academic and a commercial online resource related to health issues showed that they experienced difficulty in performing these tasks adequately, especially in the case of the commercial resource. The study also explored the relationships between online evaluation performance and offline reading ability, including measures of both fluency and comprehension. The results indicated that offline reading skills are important for online evaluation skills but not sufficient for successful critical evaluation of a commercially oriented online resource. While 
the apparent inability of many students to think critically about online information is clearly a pedagogical concern, recent work suggests that the issue may also be important for citizens in democratic countries in relation to news sources (Stanford History Education Group, 2016). There appears to be an important need for additional research both on the full extent of this issue and on instructional practices that may be used to support the development of a more critically thoughtful generation in our schools. 


\section{References}

Afflerbach, P., \& Cho, B-Y. (2010). Determining and describing reading strategies: Internet and traditional forms of reading. In H.S. Waters \& W. Schneider (Eds.), Metacognition, strategy use, and instruction (pp. 201-225). New York, NY: Guilford.

Andreassen, R., \& Strømsø, H. I. (2012). Reading about health risks: Who and what to trust? A research review. In K.P. Knutsen, S. Kvam, P.H. Langemeyer, K. Solfjeld, \& A. Parianou (Eds.), Narratives of risk: Interdisciplinary studies (pp. 255-274). Münster, Germany: Waxman.

Bates, B. R., Romina, S., Ahmed, R., \& Hopson, D. (2006). The effect of source credibility on consumers' perceptions of the quality of health information on the Internet. Medical Informatics and the Internet in Medicine, 31, 45-52.

Brassart, D. G. (1996). Does a prototypical argumentative schema exist? Text recall in 8 to 13 years olds. Argumentation, 10, 163-174.

Britt, M. A., Perfetti, C. A., Sandak, R., \& Rouet, J. F. (1999). Content integration and source separation in learning from multiple texts. In S. R. Goldman, A. C. Graesser, \& P. van den Broek (Eds.), Narrative comprehension, causality, and coherence: Essays in honor of Tom Trabasso (pp. 209-233). Mahwah, NJ: Erlbaum.

Bogdan, R. C., \& Biklen, S. K. (2003). Qualitative research for education: An introduction to theories and methods (4th ed.). Boston, MA: Allyn \& Bacon.

Brand-Gruwel, S., Wopereis, I., \& Vermetten, Y. (2005). Information problem solving by experts and novices: Analysis of a complex cognitive skill. Computers in Human Behavior, 21, 487-508.

Bråten, I., Strømsø, H. I., \& Britt, M. A. (2009). Trust matters: Examining the role of source evaluation in students' construction of meaning within and across multiple texts. Reading Research Quarterly, 44, 6-28. 
Bråten, I., McCrudden, M. T., Lund, E. S., Brante, E. W., Stømsø, H. I. (2017). Task-oriented learning with multiple documents: Effects of topic familiarity, author expertise, and content relevance on document selection, processing, and use. Reading Research Quarterly. Advance online publication. doi: 10.1002/rrq.197

Bråten, I., Strømsø, H. I., \& Salmerón, L. (2011). Trust and mistrust when students read multiple information sources about climate change. Learning and Instruction, 21, 180192.

Byron, T. (2008). Safer children in a digital world: The report of the Byron Review: Be safe, be aware, have fun. London: Department for Children, Schools and Families, and the Department for Culture, Media and Sport: London. Retrieved from http://dera.ioe.ac.uk/7332/7/Final\%20Report\%20Bookmarked_Redacted.pdf

Coiro, J. (2011a). Predicting reading comprehension on the Internet contributions of offline reading skills, online reading skills, and prior knowledge. Journal of Literacy Research, $43,352-392$.

Coiro, J. (2011b). Talking about reading as thinking: Modeling the hidden complexities of online reading comprehension. Theory Into Practice, 50, 107-115.

Coiro, J., Coscarelli, C., Maykel, C., \& Forzani, E. (2015). Investigating criteria that seventh graders use to evaluate the quality of online information. Journal of Adolescent \& Adult Literacy, 59, 287-297.

Coiro, J., \& Dobler, E. (2007). Exploring the online reading comprehension strategies used by sixth-grade skilled readers to search for and locate information on the Internet. Reading Research Quarterly, 42, 214-257.

Eastin, M. S. (2008). Toward a cognitive development approach to youth perceptions of credibility. In M.J. Metzger \& A.J. Flanagin (Eds.), Digital media, youth, and credibility (pp. 29-48). Cambridge, MA: MIT press. 
Eastin, M. S., Yang, M. S., \& Nathanson, A. I. (2006). Children of the net: An empirical exploration into the evaluation of Internet content. Journal of Broadcasting \& Electronic Media, 50, 211-230.

Eccles, J. S. (1999). The development of children ages 6 to 14. The Future of Children, 9, $30-44$.

Eklund, K., Torppa, M., Leppänen, P. H. T, \& Lyytinen, H. (2015). Literacy skill development of children with familial risk for dyslexia through grades 2,3 , and 8 . Journal of Educational Psychology, 107, 126-140.

Fabos, B. (2008). The price of information: Critical literacy, education, and today's Internet. In J. Coiro, M. Knobel, C. Lankshear, \& D.J. Leu (Eds.), Handbook of research on new literacies (pp. 839-870). New York, NY: Erlbaum.

Fogg, B. J., Soohoo, C., Danielson, D., Marable, L., Stanford, J., \& Tauber, E. R. (2002). How do people evaluate a Web site's credibility: Results from a large study. Retrieved from http://www.consumerwebwatch.org/dynamic/web-credibility-reportsevaluate-abstract.cfm.

Fuchs, L. S., Fuchs, D., Hosp, M. K., \& Jenkins, J. R. (2001). Oral reading fluency as an indicator of reading competence: A theoretical, empirical, and historical analysis. Scientific Studies of Reading, 5, 239-256.

Flanagin, A. J., \& Metzger, M. J. (2008). Digital media and youth: Unparalleled opportunity and unprecedented responsibility. In M.J. Metzger \& A. J. Flanagin (Eds.), Digital media, youth, and credibility (pp. 5-27). Cambridge, MA: MIT press.

Gasser, U., Cortesi, S., Malik, M., \& Lee, A. (2012). Youth and digital media: From credibility to information quality (February 16, 2012). Berkman Center Research Publication No. 2012-1. Retrieved from http://dx.doi.org/10.2139/ssrn.2005272.

Goldman, S. R., \& Scardamalia, M. (2013). Managing, understanding, applying, and creating 
knowledge in the information age: Next-generation challenges and opportunities. Cognition and Instruction, 31, 255-269.

Gray, N. J., Klein, J. D., Noyce, P. R., Sesselberg, T. S., \& Cantrill, J. A. (2005). Health information-seeking behaviour in adolescence: The place of the Internet. Social Science \& Medicine, 60, 1467-1478.

Hahnel, C., Goldhammer, F., Naumann, J., \& Kröhne, U. (2016). Effects of linear reading, basic computer skills, evaluating online information, and navigation on reading digital text. Computers in Human Behavior, 55, 486-500.

Hartman, D., Hagerman, M. S., \& Leu, D. J. (in press). Towards a new literacies perspective of synthesis: Multiple source meaning construction. To appear in J. Braasch and I. Bråten (Eds.), Handbook of research on multiple source use. London: Routledge.

Howe, P., \& Teufel, B. (2014). Native advertising and digital natives: The effects of age and advertisement format on news website credibility judgments. The Journal of the International Symposium on Online Journalism, 4, 78-90.

Kammerer, Y., Kalbfell, E., \& Gerjets, P. (2016). Is this information source commercially biased? How contradictions between web pages stimulate the consideration of source information. Discourse Processes, 53, 430-456.

Kervin, L., Jones, S. C., \& Mantei, J. (2012). Online advertising: Examining the content and messages within websites targeted at children. E-Learning and Digital Media, 9, 6982.

Kiili, C., Laurinen, L., \& Marttunen, M. (2008). Students evaluating Internet sources: From versatile evaluators to uncritical readers. Journal of Educational Computing Research, 39, 75-95.

Kintsch, W. (1998). Comprehension: A paradigm for cognition. New York, NY: Cambridge University Press. 
Krippendorff, K. (2004). Content analysis: An introduction to its methodology (2 ${ }^{\text {nd }}$ ed.). Thousand Oaks, CA: Sage.

Le Bigot, L.., \& Rouet, J. F. (2007). The impact of presentation format, task assignment, and prior knowledge on students' comprehension of multiple online documents. Journal of Literacy Research, 39, 445-470.

Leu , D. J. , Kinzer , C. K. , Coiro , J. , Castek , J. , \& Henry , L. A. ( 2013 ). New literacies: A dual level theory of the changing nature of literacy, instruction, and assessment. In D.E. Alvermann, N.J. Unrau \& R.B. Ruddell (Eds.), Theoretical models and processes of reading ( 6th ed., pp. 1150-1181 ). Newark, DE: International Reading Association.

Leu, D. J., Forzani, E., Rhoads, C., Maykel, C., Kennedy, C., \& Timbrell, N. (2015). The new literacies of online research and comprehension: Rethinking the reading achievement gap. Reading Research Quarterly, 50, 37-59.

Lindeman, J. 1998. Ala-asteen lukutesti ALLU [Reading test for primary school ALLU]. Turun yliopisto, oppimistutkimuksen keskus.

Macedo-Rouet, M., Braasch, J. L., Britt, M. A., \& Rouet, J. F. (2013). Teaching fourth and fifth graders to evaluate information sources during text comprehension. Cognition and Instruction, 31, 204-226.

Morahan-Martin, J. M. (2004). How Internet users find, evaluate, and use online health information: A cross-cultural review. Cyberpsychology and Behavior 7, 497-510.

Nickerson, R. S. (1998). Confirmation bias: A ubiquitous phenomenon in many guises. Review of general psychology, 2(2), 175-220.

Nevala, J., \& Lyytinen, H. (2000). Sanaketjutesti [Word chain test]. Jyväskylä: Niilo Mäki Instituutti. 
Onwuegbuzie, A. J., \& Teddlie, C. (2003). A framework for analyzing data in mixed methods research. In A. Tashakkori, \& C. Teddlie (Eds.), Handbook of mixed methods in the social and behavioral sciences (pp. 351-385). Thousand Oaks, CA: Sage.

Perfetti, C. A., Rouet, J.-F., \& Britt, M. A. (1999). Towards a theory of documents representation. In H. van Oostendorp \& S. Goldman (Eds.), The construction of mental representations during reading (pp. 99-122). Mahwah, NJ: Erlbaum.

Rouet, J. F., Le Bigot, L., de Pereyra, G., \& Britt, M. A. (2016). Whose story is this? Discrepancy triggers readers' attention to source information in short narratives. Reading and Writing, 29, 1549-1570.

Stanford History Education Group (November 22, 2016). Evaluating information: The cornerstone of civic responsibility. An executive summary. Retrieved from https://sheg.stanford.edu/upload/V3LessonPlans/Executive\%20Summary\%2011.21.16.pdf

Strømsø, H. I., Bråten, I., Britt, M. A., \& Ferguson, L. E. (2013). Spontaneous sourcing among students reading multiple documents. Cognition and Instruction, 31, 176-203.

Tseng, S., \& Fogg, B. J. (1999). Credibility and computing technology. Communications of the $A C M, 42(5), 39-44$.

van Strien, J. L., Kammerer, Y., Brand-Gruwel, S., \& Boshuizen, H. P. (2016). How attitude strength biases information processing and evaluation on the web. Computers in Human Behavior, 60, 245-252

Walraven, A., Brand-Gruwel, S., \& Boshuizen, H. P. (2009). How students evaluate information and sources when searching the World Wide Web for information. Computers \& Education, 52, 234-246.

Walton, D. N. (1991). Bias, critical doubt and fallacies. Argumentation and Advocacy, 28, 122.

Wiley, J., Goldman, S. R., Graesser, A. C., Sanchez, C. A., Ash, I. K., \& Hemmerich, J. A. 
(2009). Source evaluation, comprehension, and learning in Internet science inquiry tasks. American Educational Research Journal, 46, 1060-1106. 


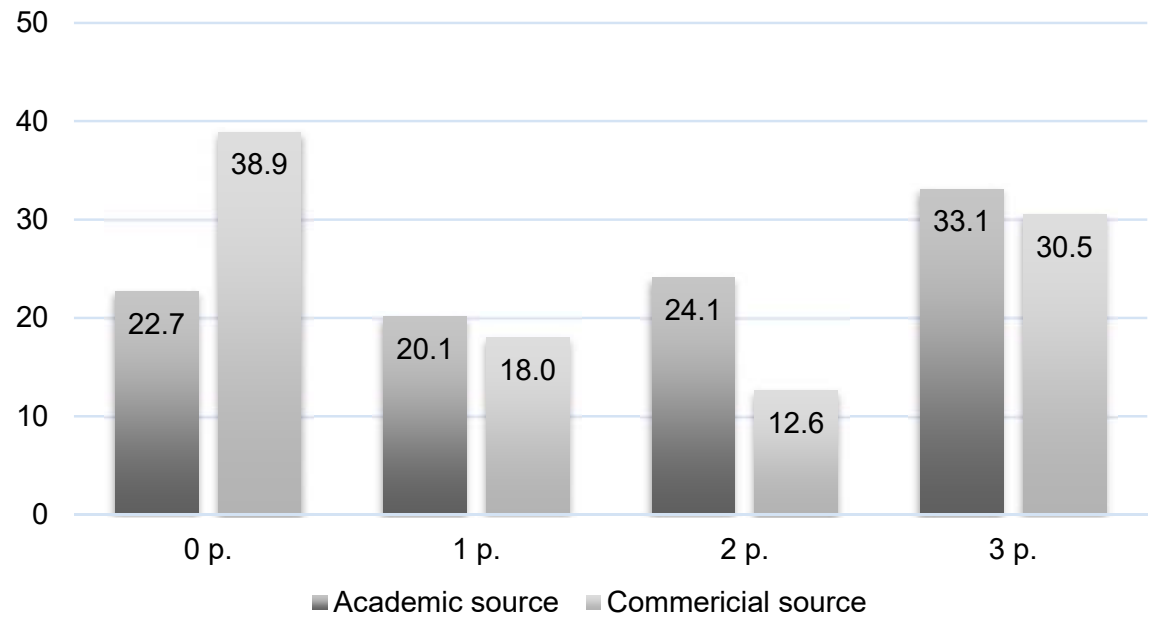

Figure 1. Students' $(n=426)$ scores for their evaluation of author expertise for the academic and commercial online resources. 
60

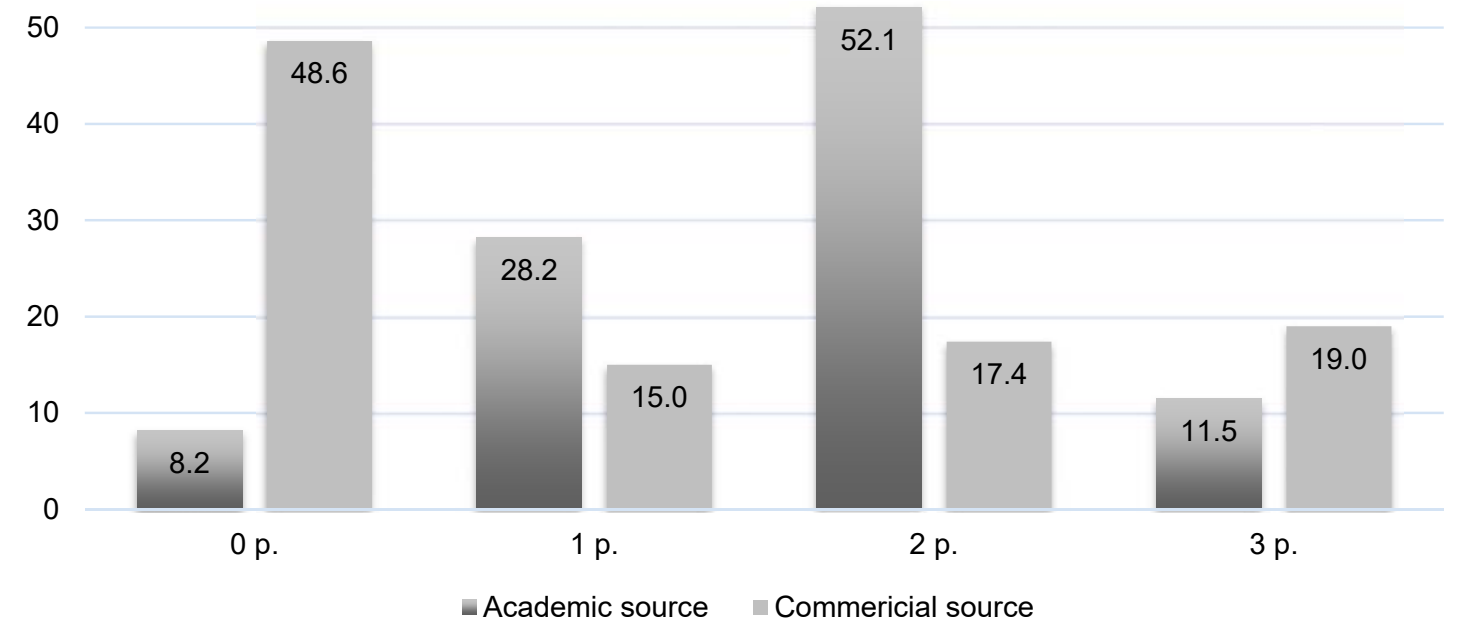

Figure 2. Students' $(n=426)$ scores for their evaluation of overall credibility for the academic and commercial online resources. 
Table 1

Scoring Criteria for Students' Evaluation of the Academic Online Resource

\begin{tabular}{|c|c|c|c|c|}
\hline Aspect of the evaluation & 0 point & 1 point & 2 points & 3 points \\
\hline $\begin{array}{l}\text { Author expertise on health issues } \\
\text { Prompt question: Is the author an } \\
\text { expert on health issues related to } \\
\text { energy drinks? Why do you think so? }\end{array}$ & $\begin{array}{l}\text { The student does not } \\
\text { explicitly or } \\
\text { implicitly state that } \\
\text { the author is an } \\
\text { expert. }\end{array}$ & $\begin{array}{l}\text { The student explicitly or } \\
\text { implicitly states that the } \\
\text { author is an expert but } \\
\text { does not justify his or } \\
\text { her statement in a } \\
\text { relevant way. }\end{array}$ & $\begin{array}{l}\text { The student explicitly or implicitly } \\
\text { states that the author is an expert. } \\
\text { The student also justifies his or her } \\
\text { statement with relevant reason(s) } \\
\text { other than the credibility labels } \\
\text { presented on the web page (such as } \\
\text { knows a lot; talks like an expert). }\end{array}$ & $\begin{array}{l}\text { The student explicitly or implicitly } \\
\text { states that the author is an expert. The } \\
\text { student also justifies his or her } \\
\text { statement by referring to credibility } \\
\text { labels (e.g. the author's research } \\
\text { background, organization, or expertise } \\
\text { on the topic) that is presented on the } \\
\text { web page. }\end{array}$ \\
\hline $\begin{array}{l}\text { Overall credibility of online resource } \\
\text { Prompt question: Is the information } \\
\text { provided on the web page credible? } \\
\text { Why do you think so? }\end{array}$ & $\begin{array}{l}\text { The student does not } \\
\text { evaluate the web page } \\
\text { or evaluates it as not } \\
\text { credible. }\end{array}$ & $\begin{array}{l}\text { The student explicitly or } \\
\text { implicitly states that the } \\
\text { web page is credible but } \\
\text { does not justify his or } \\
\text { her statement. }\end{array}$ & $\begin{array}{l}\text { The student explicitly or implicitly } \\
\text { states that the web page is credible. } \\
\text { The student also justifies his or her } \\
\text { statement with one relevant reason. }\end{array}$ & $\begin{array}{l}\text { The student explicitly or implicitly } \\
\text { states that the web page is credible. The } \\
\text { student also justifies his or her } \\
\text { statement with at least two relevant } \\
\text { reasons. }\end{array}$ \\
\hline
\end{tabular}


Table 2

Scoring Criteria for Students' Evaluation of the Commerical Online Resource

\begin{tabular}{|c|c|c|c|c|}
\hline Aspect of the evaluation & 0 point & 1 point & 2 points & 3 points \\
\hline $\begin{array}{l}\text { Author expertise on health issues } \\
\text { Prompt question: Is the author an } \\
\text { expert on health issues related to } \\
\text { energy drinks? Why do you think so? }\end{array}$ & $\begin{array}{l}\text { The student does } \\
\text { not doubt the } \\
\text { expertise of the } \\
\text { author. }\end{array}$ & $\begin{array}{l}\text { The student questions } \\
\text { the expertise of the } \\
\text { author but does not } \\
\text { justify his or her } \\
\text { judgment in a relevant } \\
\text { way. }\end{array}$ & $\begin{array}{l}\text { The student explicitly or implicitly questions } \\
\text { the expertise of the author by referring to } \\
\text { aspects of the information that the author } \\
\text { provides or does not provide (e.g. the author } \\
\text { does not tell about the negative effects of } \\
\text { energy drinks or she provides information } \\
\text { that is inconsistent with other resources). }\end{array}$ & $\begin{array}{l}\text { The student explicitly or implicitly } \\
\text { questions the expertise of the } \\
\text { author by noting that the authors' } \\
\text { expertise is related to some area } \\
\text { other than health issues (e.g. sales } \\
\text { promotion or as a representative of } \\
\text { the company). }\end{array}$ \\
\hline $\begin{array}{l}\text { Overall credibility of online resource } \\
\text { Prompt question: Is information } \\
\text { provided on the web page credible? } \\
\text { Why do you think so? }\end{array}$ & $\begin{array}{l}\text { The student does } \\
\text { not doubt the } \\
\text { credibility of the } \\
\text { web page. }\end{array}$ & $\begin{array}{l}\text { The student questions } \\
\text { the credibility of the web } \\
\text { page. The student does } \\
\text { not justify his or her } \\
\text { judgment in a relevant } \\
\text { way. }\end{array}$ & $\begin{array}{l}\text { The student questions the credibility of the } \\
\text { web page. The student does not recognize the } \\
\text { commercial bias but justifies his or her } \\
\text { critical judgment with some other relevant } \\
\text { reason(s) (e.g. one-sided information, } \\
\text { information that is inconsistent with what } \\
\text { appears on other web pages, or information } \\
\text { that is inconsistent with one's previous } \\
\text { knowledge). }\end{array}$ & $\begin{array}{l}\text { The student questions the } \\
\text { credibility of the web page. The } \\
\text { student also justifies his or her } \\
\text { judgment on the basis of } \\
\text { commercial bias. }\end{array}$ \\
\hline
\end{tabular}


Table 3

Analysis Categories of Students' Justifications for Their Overall Credibility Evaluations

\begin{tabular}{|c|c|c|}
\hline & \multirow{2}{*}{\multicolumn{2}{|c|}{ An example }} \\
\hline & & \\
\hline category & Academic online resource & Commercial online resource \\
\hline $\begin{array}{l}\text { Relevant justification - } \\
\text { Author expertise }\end{array}$ & $\begin{array}{l}\text { The information on the web page is } \\
\text { credible because }\end{array}$ & $\begin{array}{l}\text { The information on the web page is not } \\
\text { credible because }\end{array}$ \\
\hline $\begin{array}{l}\text { Organization } \\
\text { affiliated with the } \\
\text { author }\end{array}$ & $\begin{array}{l}\text { I think I can trust this web site } \\
\text { because it is owned by the } \\
\text { university (Student 159). }\end{array}$ & $\begin{array}{l}\text { The web page is composed by an energy } \\
\text { drink manufacturer, ReFresh Oy (Student } \\
216 \text { ). }\end{array}$ \\
\hline Author expertise & $\begin{array}{l}\text { A real researcher has raised a } \\
\text { diversity of issues on energy drinks } \\
\text { (Student 196). }\end{array}$ & $\begin{array}{l}\text { The author of the web page is the head of } \\
\text { communication and not an expert on } \\
\text { energy drinks (Student } 375 \text { ). }\end{array}$ \\
\hline Warrant & $\begin{array}{l}\text { At the university all information is } \\
\text { thoroughly checked (Student 286). }\end{array}$ & --- \\
\hline Other & $\begin{array}{l}\text { Parents have also asked her [the } \\
\text { author] for information (Student } \\
473 \text { ). }\end{array}$ & --- \\
\hline \multicolumn{3}{|c|}{$\begin{array}{l}\text { Relevant justification - } \\
\text { Trustworthiness of the content }\end{array}$} \\
\hline Use of sources & $\begin{array}{l}\text { Marika Virtanen has explored the } \\
\text { issue with sources that seem to be } \\
\text { reliable (Student 119). }\end{array}$ & $\begin{array}{l}\text { It does not provide any sources, so the } \\
\text { information can be made-up (Student } \\
\text { 173). }\end{array}$ \\
\hline Pertinence & $\begin{array}{l}\text { The text is also good and pertinent } \\
\text { that gives a credible picture of the } \\
\text { page (Student 103). }\end{array}$ & --- \\
\hline $\begin{array}{l}\text { Research basis of } \\
\text { information }\end{array}$ & $\begin{array}{l}\text { The page uses official research- } \\
\text { based information (Student 235). }\end{array}$ & $\begin{array}{l}\text { They have not conducted any research on } \\
\text { the issue (Student 514). }\end{array}$ \\
\hline $\begin{array}{l}\text { Correspondence with } \\
\text { the other resources }\end{array}$ & $\begin{array}{l}\text { The previous page provided similar } \\
\text { information (Student 119). }\end{array}$ & $\begin{array}{l}\text { According to all other sources, energy } \\
\text { drinks are harmful to health (Student } \\
\text { 321). }\end{array}$ \\
\hline $\begin{array}{l}\text { Correspondence with } \\
\text { one's previous } \\
\text { knowledge }\end{array}$ & $\begin{array}{l}\text { I have heard about the same issues } \\
\text { from my mother and other relatives. } \\
\text { I know by myself that energy drinks } \\
\text { are not good for your health } \\
\text { (Student 446). }\end{array}$ & $\begin{array}{l}\text { Energy drinks are very unhealthy } \\
\text { (Student 168). }\end{array}$ \\
\hline
\end{tabular}


Purpose of the online resource

Balance of argumentation

Warrant

Other

Irrelevant justification
If someone wants to know about energy drinks, this page will be helpful. Parents could use this page, if a child wants to consume energy drinks and they don't know how energy drinks can affect children or adolescents (Student 540)

$---$

Sources that one can check are given at the bottom of page(Student 158).

I have read the information thoroughly (Student 186).
The web page is only trying to advertise energy drinks (Student 501).

It only tells about the positive sides of energy drinks (Student 384).

They are trying to sell a product and do not necessarily tell about the health risks (Student 172).

It does not state at all where it comes from, what it includes or other similar issues (Student 182).

The web page does not look credible (Student 155). 
Table 4

Means, Standard Deviations, and Skewness for Measured Background Variables

\begin{tabular}{lrrrr}
\hline Measure & $n$ & $M$ & SD & Skewness \\
\hline Word chain test (max. 100 points)* $^{*}$ & 419 & 42.81 & 14.50 & 0.39 \\
Pseudoword reading fluency test (correctly read words/time)* & 424 & 0.70 & 0.21 & 0.39 \\
Word identification test (max. 80 points)* $^{*}$ & 422 & 48.42 & 9.34 & 0.19 \\
Reading comprehension test (n = 422; max 12 points) & 422 & 6.91 & 2.53 & 0.02 \\
Prior knowledge measure (max. 7 points) & 426 & 4.48 & 1.46 & -0.45 \\
\hline
\end{tabular}

Note. *Variables used to form a reading fluency factor score. 


\section{Table 5}

Crosstab of Scores on Evaluation of Overall Credibility of the Academic Online Resource with Scores on the Commercial Online Resource Including Observed Frequencies, Expected Frequencies and Percentages

\begin{tabular}{lrrrrr}
\hline & \multicolumn{5}{c}{ Scores on commercial online resource } \\
\hline Scores on academic online resource & 0 point & 1 point & 2 points & 3 points & Total \\
\hline 0 point & & & & & \\
Observed frequency & 24.0 & 7.0 & 4.0 & 0.0 & 35.0 \\
Expected frequency & 17.0 & 5.3 & 6.1 & 6.7 & 35.0 \\
$\%$ & 68.6 & 20.0 & 11.4 & 0.0 & 100.0 \\
& & & & & \\
1 point & & & & & \\
Observed frequency & 57.0 & 21.0 & 23.0 & 19.0 & 120.0 \\
Expected frequency & 58.5 & 18.0 & 20.8 & 22.8 & 120.0 \\
$\%$ & 47.5 & 17.5 & 19.2 & 15.8 & 100.0 \\
& & & & & \\
Oboints & 111.0 & 33.0 & 38.0 & 40.0 & 222.0 \\
Expected frequency & 109.1 & 33.6 & 38.8 & 42.5 & 222.0 \\
$\%$ & 50.0 & 14.9 & 17.1 & 18.0 & 100.0 \\
& & & & & \\
3 points & 15.0 & 3.0 & 9.0 & 22.0 & 49.0 \\
Observed frequency & 23.9 & 7.3 & 8.5 & 9.3 & 49.0 \\
Expected frequency & 30.6 & 6.1 & 18.4 & 44.9 & 100.0 \\
$\%$ & 207 & 64 & 74 & 81 & 426 \\
\hline Total & & & &
\end{tabular}


EVALUATION OF ONLINE RESOURCES

Table 6

Students' Justifications for Overall Credibility Evaluations of the Academic and Commercial

Online Resources

\begin{tabular}{|c|c|c|c|c|}
\hline \multirow[b]{3}{*}{ Justification category } & \multicolumn{4}{|c|}{ Justification for } \\
\hline & \multicolumn{2}{|c|}{$\begin{array}{r}\text { Credibility of } \\
\text { the academic resource } \\
(n=355)\end{array}$} & \multicolumn{2}{|c|}{$\begin{array}{r}\text { Lack of credibility of } \\
\text { the commercial } \\
\text { resource } \\
(n=192)\end{array}$} \\
\hline & $f$ & & $f$ & $\%$ \\
\hline \multicolumn{5}{|l|}{ Relevant justification } \\
\hline \multicolumn{5}{|l|}{ Author expertise } \\
\hline Organization affiliated with the author & 113 & 28.46 & 12 & 5.85 \\
\hline Author expertise & 89 & 22.42 & 9 & 4.39 \\
\hline Warrant & 10 & 2.52 & 0 & 0 \\
\hline Other & 4 & 1.01 & 0 & 0 \\
\hline Author expertise, total & 216 & 54.41 & 21 & 10.24 \\
\hline \multicolumn{5}{|l|}{ Trustworthiness of the content } \\
\hline Use of sources & 44 & 11.09 & 6 & 2.93 \\
\hline Pertinence & 20 & 5.04 & 0 & 0 \\
\hline Research-basis of information & 15 & 3.78 & 1 & 0.49 \\
\hline Correspondence with one's previous knowledge & 13 & 3.27 & 23 & 11.22 \\
\hline Corroboration with the other online resources* & 12 & 3.02 & 23 & 11.22 \\
\hline Purpose of the online resource* & 2 & 0.50 & 81 & 39.51 \\
\hline Warrant & 1 & 0.25 & 6 & 2.93 \\
\hline Balance of argumentation* & 0 & 0 & 7 & 3.41 \\
\hline Other & 0 & 0 & 3 & 1.46 \\
\hline Trustworthiness of the content total & 107 & 26.95 & 150 & 73.17 \\
\hline Relevant justification total & 323 & 81.36 & 171 & 83.41 \\
\hline Irrelevant justification & 74 & 18.64 & 34 & 16.59 \\
\hline Total & 397 & 100 & 205 & 100 \\
\hline
\end{tabular}

Note. A student may have provided more than one justification.

*Elements of bias in the case of the commercial online resource. 


\section{Table 7}

Logistic Regressions Predicting Students' Performance on Evaluating Overall Credibility of the Academic and Commercial Online Resources

\begin{tabular}{lrrrrrr}
\hline & $\begin{array}{r}\text { Model } \chi 2 \\
(d f)\end{array}$ & $p$ & $\begin{array}{r}\text { Nagelkerke's } \\
R^{2}\end{array}$ & OR & $p$ & $95 \% C I$ \\
\hline $\begin{array}{l}\text { Academic online resource } \\
\text { A. Credibility of information }\end{array}$ & $27.449(2)$ & $<.001$ & .088 & & & \\
$\quad \begin{array}{l}\text { Reading fluency } \\
\text { Reading comprehension }\end{array}$ & & & & 1.167 & ns. & $.908-1.499$ \\
& & & & 1.212 & $<.001$ & $1.106-1.328$ \\
Commercial online resource & & & & & & \\
B. Credibility of information & $48.456(2)$ & $<.001$ & .151 & & & \\
$\quad \begin{array}{l}\text { Reading fluency } \\
\text { Reading comprehension }\end{array}$ & & & & 1.466 & .003 & $1.136-1.891$ \\
& & & & 1.242 & $<.001$ & $1.131-1.364$
\end{tabular}

Note. $\mathrm{OR}=$ Odds ratio; $\mathrm{CI}=$ Confidence interval. 
